\title{
Genital infection with Ureaplasma urealyticum and its effect on pregnancy
}

\author{
DANIELA ROXANA MATASARIU ${ }^{1}$, ALEXANDRA URSACHE ${ }^{1}$, ALINA AGACHE ${ }^{1}$, \\ CRISTINA ELENA MANDICI ${ }^{1}$, VASILE LUCIAN BOICULESE ${ }^{2}$, IULIANA ELENA BUJOR ${ }^{3}$, \\ DORINA RUDISTEANU ${ }^{3}$, IRINA DUMITRASCU ${ }^{1,3}$ and CARMINA MIHAIELA SCHAAS ${ }^{1,3}$
}

\begin{abstract}
Departments of ${ }^{1}$ Obstetrics and Gynecology and ${ }^{2}$ Preventive Medicine and Interdisciplinary Medical Informatics and Biostatistics, 'Grigore T. Popa' University of Medicine and Pharmacy, 700115 Iasi; ${ }^{3}$ Department of Obstetrics and Gynecology,

'Cuza Voda' Obstetrics and Gynecology Clinical Hospital, 700038 Iasi, Romania
\end{abstract}

Received August 25, 2021; Accepted September 24, 2021

DOI: 10.3892/etm.2021.11012

\begin{abstract}
Chorioamnionitis or intra-amniotic infection is an infection that affects the intrauterine content during pregnancy. Numerous studies have reported vaginal colonization with various types of infectious agents as a risk factor for chorioamnionitis. Although this complication occurs due to the ascending polymicrobial bacterial infection at the time of membrane breakage, it may also occur in pregnant women with intact membranes, mainly due to Ureaplasma urealyticum (U. urealyticum) and Mycoplasma hominis (M. hominis). The main aim of the present study was to identify a region-specific panel of infectious agents that can be used more accurately determine premature birth, as well as the premature rupture of membranes (PROM). Thus, a 10-year retrospective study was conducted. A total of 1,301 pregnant women with PROM and premature birth or spontaneous abortion were included in the study. It was observed that the main infectious agent varied in the five groups analyzed in total. The infectious agent distribution also varied depending on environmental parameters. Ureaplasma was found to be the most frequently detected germ amongst the infectious agents of the vaginal cultures from pregnant women enrolled in the present study, regardless of gestational age. On the whole, the findings of the present study suggest that additional studies are required, in order to confirm that diagnosis and treatment according to laboratory
\end{abstract}

Correspondence to: Dr Alexandra Ursache, Department of Obstetrics and Gynecology, 'Grigore T. Popa' University of Medicine and Pharmacy, Street Universitatii 16, 700115 Iasi, Romania E-mail: carpalecsandra@yahoo.com

Abbreviations: PROM, premature rupture of membranes; E. coli, Escherichia coli; U. urealyticum, Ureaplasma urealyticum; M. hominis, Mycoplasma hominis; BV, bacterial vaginosis; PTB, preterm birth

Key words: chorioamnionitis, infection, pregnancy, Ureaplasma species, premature rupture of membranes, preterm birth results of vaginal infections with $U$. urealyticum/M. hominis during the first trimester of pregnancy could prevent premature birth, abortion or chorioamnionitis.

\section{Introduction}

It has been proven that vaginal infections may negatively affect pregnancy, leading to complications such as spontaneous abortion, premature rupture of membranes (PROM), preterm delivery, intrauterine growth restriction, intrauterine death, neonatal infections and postpartum infections (1-7). Genital tract infections in pregnancy account for $\sim 15 \%$ of first trimester miscarriages and $66 \%$ of late miscarriages $(8,9)$. In addition, the implication of infection in the etiology of recurrent loss remains unclear, with an incidence of $0.5-5 \%(8,10)$.

The microorganisms most frequently involved in women genital tract infections are group B Streptococcus, Escherichia coli (E. Coli), Enterococcus faecalis, Enterobacter spp., Candida spp., Ureaplasma urealyticum (U. urealyticum), Mycoplasma hominis (M. hominis), Chlamydia trachomatis and bacterial vaginosis (BV; a disruption in the normal vaginal flora with less or absent Lactobacilli and consequent infection with Gram-negative bacteria) $(1,4)$. A previously published revealed the importance of normal vaginal microflora and the negative impact of bacterial vaginosis on pregnancy outcomes (5). Emerging evidence has indicated that the presence of Candida and BV in pregnancy may increase the risk of abortion and preterm birth (PTB). Vaginosis in pregnancy can lead to a series of severe complications, such as spontaneous abortion, preterm delivery, chorioamnionitis, low birth weight and endometritis (1,11-13).

$U$. urealyticum infection has been identified in the urogenital tract of both healthy and symptomatic women (14), having been isolated from asymptomatic healthy women and also from amniotic fluid (15), and associated with chorioamnionitis in only a few cases (16). According to the pathogenesis, the evasion of the local immune response has been suggested. Endometrial immunity is activated by bacterial infections and an intense immune response follows, affecting the beginning of a pregnancy $(2,8)$. Further evidence recently emerged in favor of the association between $U$. urealyticum, alone or 
in combination with $M$. hominis and obstetrical pregnancy complications, including premature rupture of membranes, preterm delivery and abortion (17). However, there is controversy concerning the specific role of Mycoplasma species in adverse pregnancy outcomes $(8,18)$.

Previous studies have revealed that the prevalence of Mycoplasma in the genital tract of women in a population is affected by a number of aspects, including age, race, socio-economic status, use of contraceptives, menstruation, menopausal changes and pregnancy (19-21). Immunological and hormonal changes attributed to pregnancy may also affect vaginal colonization. Animal research has demonstrated the influence of estrogen and progesterone on vaginal colonization by different types of Mycoplasma and Ureaplasma (18). To determine the real prevalence of $U$. urealyticum in the genital tract of pregnant women compared with non-pregnant women, all the aforementioned factors need to be taken into consideration. For this reason, reliable data are not yet available, although these species of infectious agents are identified more often in pregnant than in non-pregnant women. The prevalence of $U$. urealyticum infection in the general community is also affected by the same factors, not being precisely established $(19,21)$.

PTB is defined as delivery before the 37 th week of gestation according to the last menstrual period of a woman and the data provided by ultrasound (22,23). PTB can be classified according to gestational age as follows: i) Ranging from 24-28 weeks of gestation as extremely preterm; ii) from 29-32 weeks of gestation as very preterm; and iii) from 32-36 weeks of gestation as moderately or late-preterm $(24,25)$. PTB is the major cause of neonatal morbidity and mortality (24). It has an annual global incidence of $\sim 15$ million cases. PTB is classified as spontaneous preterm labor, PROM and medically induced PTB, determined by feto-maternal complications (23). The ethology of PTB is multifactorial; however, infection and/or inflammation remain the only etiologies that have a solid evidenced-based background $(22,23)$.

Half of all PTBs occurring prior to 30 weeks of pregnancy are clearly attributed to chorioamnionitis. Ureaplasma and Mycoplasma species remain the most commonly isolated infectious agents associated with chorioamnionitis, regardless of gestational age $(26,27)$. The risk of developing chorioamnionitis is increased in pregnant women with a temperature $>38^{\circ} \mathrm{C}$ and/or one or more of the following clinical signs: Maternal leukocytosis $\left(>15,000\right.$ cells $\left./ \mathrm{mm}^{3}\right)$, maternal and/or fetal tachycardia and purulent leukorrhea $(28,29)$. The aim of the present study was to identify a region-specific panel of infectious agents that may be used to more frequently determine abortion, PTB and PROM.

\section{Patients and methods}

Patient data collection. The present retrospective observational study was conducted at the Iasi 'Cuza Voda' University Hospital of Obstetrics and Gynecology (Iasi, Romania), in a tertiary obstetrics referral center in Northeastern Romania. A total of 1,301 women with ruptured membranes and with pregnancies $>17$ weeks of gestation were enrolled in the study, between January, 2010 to December, 2019. The corresponding demographic data included age, residency, obstetric pregnancy and current symptoms when the patient was admitted to the center. All women provided a written informed consent for study participation prior to sample collection. Ethical approval was obtained from the Ethics Committee of 'Cuza Voda' Obstetrics and Gynecology Clinical Hospital (Approval no. 10426/2021).

Eligibility criteria included a singleton intrauterine pregnancy, a gestational age ranging between 17 weeks, 0 days and 40 weeks, 0 days at the time of enrolment, a maternal age $>23$ years and admission for delivery at the 'Cuza Voda' Iasi University Hospital. Gestational age was determined by last menstrual period declared by the patient, in association with the ultrasound data. The exclusion criteria included the following: The existence of any genetic disorders, birth defects and antibiotic treatment within 1 month prior to the study. Women with any mental disabilities were not included in the study.

Patient sample collection. Vaginal fluid samples were obtained from the enrolled participants prior to antibiotic treatment at the time of admission to the obstetrics referral center. Samples were collected without the use of antiseptics and cultures were performed. Patients were categorized into 5 groups according to gestational age as follows: i) group 1, ranging between 17-23 weeks of gestation; ii) group 2, 24-28 weeks of gestation; iii) group 3, 29-32 weeks of gestation; iv) group 4, 33-36 weeks of gestation; and v) group 5, $\geq 37$ weeks of gestation. Blood samples from all patients were collected in search for infection response (leukocytosis). All patients were also monitored for fever.

The primary outcome was preterm delivery prior to 37 weeks of gestation, whereas the secondary outcomes were delivery after 37 weeks of gestation and chorioamnionitis. Pregnant women were classified depending on their age and the gestational age of the pregnancy at the time of admission. The most frequently involved infectious agent associated with preterm delivery, chorioamnionitis and the implication of M. hominis/U. Urealyticum were also investigated in the pathological evaluation. Since infection plays a crucial role in the initiation of PTB, it was investigated whether an infectious agent mostly associated with PTB and/or chorioamnionitis could be detected, depending on confounding variables (age, residency and gestational age).

Detection of pathogens. For Ureaplasma and Mycoplasma detection, bioMérieux kits (REF42505) were used, with cultures performed on a selective medium (bioMérieux Mycoplasma IST 2 containing 25 strips of 22 tests, $25 \mathrm{R} 1$ vials and 25 lyophilised R2 vials) that inhibits commensal flora by the addition of antibiotics and antifungal agents (bioMérieux-Lincomicina, Eritromicina), using urea substrate (bioMérieux) for Ureaplasma and arginine substrate (bioMérieux) or Mycoplasma. For the detection of the other bacteria involved in genital infections in pregnant women, selective and differential culture mediums (Macconkey Agar, Oxoid; Clumbia Agar and sheep blood, Oxoid; Sabouraud glucose selective agar with gentamicin and chloramphenicol, Oxoid) were used, and for bacterial identification we utilized a MicroScan WalkAway analyzer manufactured by Beckman Coulter, Inc. For fungal detection, an ELITech CANDIFAST ${ }^{\circledR}$ kit was used. 
Statistical analysis. SPSS version 18 (PASW Statistics for Windows, SPSS, Inc.) was used for the statistical analysis. Categorical variables are presented as absolute and relative frequencies and for comparisons, the Chi-squared test was used. A P-value $\leq 0.05$ was considered to indicate a statistically significant difference.

\section{Results}

Several particularities depending on the environment were observed. All patients were classified according to gestational age as follows: i) Group 1: between 17-23 weeks of gestation; ii) group 2: between 24-28 weeks of gestation; iii) group 3 : between 29-32 weeks of gestation; iv) group 4: between 33-36 weeks of gestation; and v) group 5: $\geq 37$ weeks of gestation. Among the patients included in the study: i) $70.3 \%$ of the patients in group 1 originated from rural areas and $29.7 \%$ from urban areas; ii) $54.3 \%$ of patients in group 2 originated from rural areas and $45.7 \%$ from urban areas; iii) $41.5 \%$ of patients in group 3 were from rural areas and $58.5 \%$ from urban areas; iv) $45 \%$ of patients in group 4 were from rural areas and 55\% from urban areas; and iv) $46.5 \%$ of patients in group 5 originated from rural areas and $53.5 \%$ from urban areas (Table I). The Chi-squared test was applied to verify whether the proportions of patients from the rural and urban areas were equal. A statistically significant value of $<0.001$ was obtained, with the majority of the cases being from rural areas. However, the proportions were relatively close (total patients from urban area $46.7 \%$ and rural area $53.3 \%$ ).

It was also noted that the bacteria detected in the vaginal cultures of the patients included in the present study varied between the five groups. U. Urealyticum was detected in: i) $57.3 \%$ of the vaginal cultures of patients between 17 and 23 weeks of gestation; ii) in $49.7 \%$ of patients between 24-28 weeks of gestation; iii) in $40.7 \%$ of patients between 29-32 weeks of gestation; iv) in $40.2 \%$ of patients between 33-36 weeks of gestation; v) in $45.1 \%$ in patients $\geq 37$ weeks of gestation. E. coli was also encountered in the patient cultures as follows: $27.2 \%$ in group 1,26.8\% in group 2,30.9\% in group 3 ; and at a similar percentage of $33.3 \%$ in groups 4 and 5 . Streptococcus had a lower implication in the occurrence of vaginitis: i) $5.9 \%$ in group 1 ; ii) $13.5 \%$ in group 2; iii) $19.3 \%$ in group 3 ; iv) $18 \%$ in group 4; and v) $11.8 \%$ in group 5 . Additionally, Candida infection was involved in vaginitis, of which higher percentages were observed: i) $38.7 \%$ in group 1 ; ii) $33.2 \%$ in group 2; iii) $23.3 \%$ in group 3 ; iv) $31.2 \%$ in group 4 ; and v) $25 \%$ in group 5 . The alteration of the vaginal flora due to the appearance of vaginosis was observed in similar percentages in the first four groups: $8.4 \%$ in group 1,8.6\% in group 2, 8.4\% in group 3,7.9\% in group 4 and at a lower percentage (6.3\%) in group 5. Enterobacter infection was detected as follows: $3.1 \%$ in group 1,3\% in group 2, $2.2 \%$ in group $3,3.7 \%$ in group 4 , and $2.8 \%$ in group 5 . Enterococcus infection was as follows: $1.5 \%$ in group $1,5.1 \%$ in group 2 , $8 \%$ in group $3,6.9 \%$ in group 4 , and $3.5 \%$ in group 5 , with statistically significant differences when analyzing the data using the Chi-squared test (0.004) (Table I).

In the present study, the percentages of pregnant women with fever and/or leukocytosis were as follows: $42.4 \%$ with leukocytosis and $43.3 \%$ fever in group 1,39.7\% with leukocytosis and the same percentage with fever in group $2,35.6 \%$ with leukocytosis and $36.7 \%$ with fever in group 3, 34.9\% with leukocytosis and $35.4 \%$ with fever group 4 and finally $43.1 \%$ with leukocytosis and $44.4 \%$ with fever in group 5 . Several particularities were also observed, concerning the distribution of chorioamnionitis in these five groups, in relation to environmental parameters. The current data revealed higher percentages of this pathology in the first two groups in cases from rural areas (70.1 and 52.7\%) compared with higher percentages of chorioamnionitis in cases from urban areas in pregnancies with a gestational age $>29$ weeks $(58.2,66.7$ and $53.2 \%$ in groups 3,4 and 5 , respectively), but the differences were not statistically significant. (Table II).

U. urealyticum was detected in the vaginal cultures of pregnant women enrolled in the present study as follows: of the patients with chorioamnionitis, in group $1,54.7 \%$ had $U$. urealyticum infection; in group $2,45.9 \%$ had $U$. urealyticum infection; in group $3,40.8 \%$ had $U$. urealyticum infection; in group 4, 34.9\% had U. urealyticum infection; and in group 5, $41.9 \%$ had $U$. urealyticum infection. However, the presence of $U$. urealyticum in the vaginal cultures of patients without signs of chorioamnionitis was also detected. The bacteria most frequently detected in patient vaginal cultures regardless of the gestational age, was $U$. urealyticum.

Other bacteria more frequently involved in chorioamnionitis were as follows: Streptococcus, with an incidence of $9.5 \%$ in group $1,15.8 \%$ in group $2,13.3 \%$ in group $3,15.2 \%$ in group 4 and $12.9 \%$ in group $5 ; E$. coli with an incidence of $27.0 \%$ in group $1,26.0 \%$ in group $2,33.7 \%$ in group $3,30.3 \%$ in group 4 and $32.3 \%$ in group 5; Candida spp. in $40.9 \%$ cases from group 1,29.5\% cases from group 2, 24.5\% from cases in group 3, in $27.3 \%$ cases from group 4 and in $11.3 \%$ from group 5. Furthermore, vaginosis was detected in $7.3 \%$ of cases from group 1, in $11.6 \%$ of cases from group 2, in $11.2 \%$ of cases from group 3, in $9.1 \%$ of cases from group 4 and in $9.7 \%$ of cases from group 5 (Table III).

No marked association was noted between BV and $U$. urealyticum in the present study; however, a notable association between Candida spp. and U. urealyticum was detected in $28.5 \%$ of the cases in group 1 , in $25.9 \%$ of then cases in group 2, in $16 \%$ of the cases in group 3, in $19.0 \%$ of the cases in group 4 and in $15.3 \%$ of the cases from group 5 (Table IV).

\section{Discussion}

PTB remains the leading cause of perinatal morbidity and mortality, affecting $\sim 10 \%$ of pregnancies worldwide. The percentage varies, depending on a multitude of factors, such as ethnicity, race and socioeconomic conditions (19). The infectious agents associated with ruptured membranes and abortion or premature delivery are $C$. trachomatis, $N$. gonorrhoeae and $M$. hominis/U. urealyticum. The detection of $M$. hominis and $U$. urealyticum in vaginal cultures is associated with chorioamnionitis, premature birth and spontaneous abortion (30).

Previously published data by Capoccia et al (31) indicated that $U$. urealyticum infection in pregnancy was detected in almost half of the preterm cases. The detection of $U$. urealyticum in the amniotic fluid of pregnant women increases the risk of clinical or histological chorioamnionitis and PTB $(22,32,33)$. The accuracy in the establishment of the 
Table I. Distribution of patients according to gestational age, area and infectious agents.

\begin{tabular}{lcccccc}
\hline \multicolumn{5}{c}{ Gestational age (weeks) } & \\
\cline { 2 - 4 } Parameter & $\begin{array}{c}17-23(\mathrm{n}=323), \\
\text { count }(\%)\end{array}$ & $\begin{array}{c}24-28(\mathrm{n}=370), \\
\text { count }(\%)\end{array}$ & $\begin{array}{c}29-32(\mathrm{n}=275), \\
\text { count }(\%)\end{array}$ & $\begin{array}{c}33-36(\mathrm{n}=189), \\
\text { count }(\%)\end{array}$ & $\begin{array}{c}\geq 37(\mathrm{n}=144), \\
\text { count }(\%)\end{array}$ & $\begin{array}{c}\text { Significance } \\
\text { (P-value) }\end{array}$ \\
\hline Area of residency & & & & & \\
$\quad$ Rural & $227(70.3)$ & $201(54.3)$ & $114(41.5)$ & $85(45.0)$ & $67(46.5)$ & $<0.001$ \\
$\quad$ Urban & $96(29.7)$ & $169(45.7)$ & $161(58.5)$ & $104(55.0)$ & $77(53.5)$ & \\
Ureaplasma urealyticum & $185(57.3)$ & $184(49.7)$ & $112(40.7)$ & $76(40.2)$ & $65(45.1 \%)$ & $<0.001$ \\
infection & & & & & & \\
Streptococcus infection & $19(5.9)$ & $50(13.5)$ & $53(19.3)$ & $34(18.0)$ & $17(11.8)$ & $<0.001$ \\
Escherichia coli infection & $88(27.2)$ & $99(26.8)$ & $85(30.9)$ & $63(33.3)$ & $48(33.3)$ & 0.314 \\
Enterobacter infection & $10(3.1)$ & $11(3.0)$ & $6(2.2)$ & $7(3.7)$ & $4(2.8)$ & 0.912 \\
Enterococcus infection & $5(1.5)$ & $19(5.1)$ & $22(8.0)$ & $13(6.9)$ & $5(3.5)$ & 0.004 \\
Bacterial vaginosis & $27(8.4)$ & $32(8.6)$ & $23(8.4)$ & $15(7.9)$ & $9(6.3)$ & 0.930 \\
Candida infection & $125(38.7)$ & $123(33.2)$ & $64(23.3)$ & $59(31.2)$ & $36(25.0)$ & 0.001 \\
\hline
\end{tabular}

Table II. Distribution of patients with chorioamnionitis according to residence area and gestational age.

\begin{tabular}{|c|c|c|c|c|c|c|}
\hline \multirow[b]{2}{*}{ Parameter } & \multicolumn{5}{|c|}{ Gestational age (weeks) } & \multirow[b]{2}{*}{$\begin{array}{c}\text { Significance } \\
\text { (P-value) }\end{array}$} \\
\hline & $\begin{array}{c}17-23(\mathrm{n}=323), \\
\text { count }(\%)\end{array}$ & $\begin{array}{c}24-28(\mathrm{n}=370) \\
\text { count }(\%)\end{array}$ & $\begin{array}{c}29-32(\mathrm{n}=275) \\
\text { count }(\%)\end{array}$ & $\begin{array}{c}33-36(n=189), \\
\text { count }(\%)\end{array}$ & $\begin{array}{l}\geq 37(\mathrm{n}=144), \\
\quad \operatorname{count}(\%)\end{array}$ & \\
\hline $\begin{array}{l}\text { Leukocytosis } \\
\left(>15,000 \text { cells } / \mathrm{mm}^{3}\right)\end{array}$ & $137(42.4)$ & $147(39.7)$ & $98(35.6)$ & $66(34.9)$ & $62(43.1)$ & 0.262 \\
\hline Fever & $140(43.3)$ & 147 (39.7) & $101(36.7)$ & $67(35.4)$ & $64(44.4)$ & 0.235 \\
\hline \multicolumn{7}{|l|}{ Chorioamnitis } \\
\hline Total & $137(42.4)$ & $146(39.5)$ & 98 (35.6) & 66 (34.9) & $62(43.1)$ & 0.265 \\
\hline Rural residency & $96(70.1)$ & $77(52.7)$ & $41(41.8)$ & $22(33.3)$ & $29(46.8)$ & $<0.01$ \\
\hline Urban residency & $41(29.9)$ & $69(47.3)$ & $57(58.2)$ & $44(66.7)$ & $33(53.2)$ & \\
\hline
\end{tabular}

diagnosis of chorioamnionitis with $U$. urealyticum in pregnancy is strongly suggested. There are increasingly available data that underline the implications of this infectious agent in PTB (22).

In the present study, infection with $U$. urealyticum was the most frequent one in pregnancy, regardless of whether having been associated with chorioamnionitis or not. This conclusion is also supported by the study by Cassel et al (34), according to which $U$. urealyticum was the most frequently detected microorganism in the amniotic fluid of pregnant women. This infection was associated with preterm delivery, involving higher perinatal mortality and morbidity rates. Candida was the most frequently associated vaginitis in the present study. Additionally, co-infection was associated with an increased risk of PTB and chorioamnionitis. The data obtained herein are in disagreement with those in the study by Cassel et al that detected the presence of $\mathrm{BV}$, in association with $U$. urealyticum vaginitis, as being the most frequently associated pathology with PTB and chorioamnionitis (34).

The main cause of PTB is female upper genital tract infection $(24,35)$. Almost $30 \%$ of women experience an upper genital tract infection during pregnancy. Data from the literature suggest that $25-40 \%$ of all PTBs have something in common, infection with $U$. urealyticum $(24,32,33)$. In previous studies on PTB from the literature, the rate of $U$. urealyticum infection has been reported to be $\sim 42 \%$. The implications of $U$. urealyticum infection in this pathology are very complex, as upper genital female tract infections that occur $<32$ weeks of gestation are frequently polymicrobial $(24,25,36)$. The decreased virulence of this infectious agent accounts for the absence of clinical symptoms in a variety of cases. This may explain the chronicity that can be observed in some of the cases, with $U$. urealyticum infection being able to persist for several weeks in the upper female genital tract before preterm labor or rupture membranes occur (37).

Additionally, differences between the most frequently involved infectious agents in chorioamnionitis depending on the environment and the gestational age were detected in the present study. This difference may be attributed to changes in immune response of women and the presence of a specific vaginal bacteria, as opposed to the presence or absence of bacterial species $(38,39)$. As Bhat et al $(39)$ demonstrated in 
Table III. The most frequent infectious agents involved in chorioamnionitis according to gestational age.

\begin{tabular}{lccccc}
\hline & \multicolumn{5}{c}{ Gestational age (weeks) } \\
\cline { 2 - 6 } Parameter & $\begin{array}{c}17-23(\mathrm{n}=137), \\
\text { count }(\%)\end{array}$ & $\begin{array}{c}24-28(\mathrm{n}=146), \\
\text { count }(\%)\end{array}$ & $\begin{array}{c}29-32(\mathrm{n}=98), \\
\text { count }(\%)\end{array}$ & $\begin{array}{c}33-36(\mathrm{n}=66), \\
\text { count }(\%)\end{array}$ & $\begin{array}{c}\geq 37(\mathrm{n}=62), \\
\text { count }(\%)\end{array}$ \\
\hline Ureaplasma urealyticum infection & $75(54.7)$ & $67(45.9)$ & $40(40.8)$ & $28(42.4)$ & $26(41.9)$ \\
Streptococcus infection & $13(9.5)$ & $23(15.8)$ & $13(13.3)$ & $10(15.2)$ & $8(12.9)$ \\
Escherichia coli infection & $37(27.0)$ & $38(26.0)$ & $33(33.7)$ & $20(30.3)$ & $20(32.3)$ \\
Enterobacter infection & $9(6.6)$ & $4(2.7)$ & $3(3.1)$ & $2(3.0)$ & $1(1.6)$ \\
Enterococcus infection & $1(0.7)$ & $7(4.8)$ & $7(7.1)$ & $5(7.6)$ & $2(3.2)$ \\
Bacterial vaginosis & $10(7.3)$ & $17(11.6)$ & $11(11.2)$ & $6(9.1)$ & $6(9.7)$ \\
Candida infection & $56(40.9)$ & $43(29.5)$ & $24(24.5)$ & $18(27.3)$ & $7(11.3)$
\end{tabular}

Table IV. Dependence of Ureaplasma urealyticum infection and candida/bacterial vaginosis association levels on gestational age.

\begin{tabular}{lccccc}
\hline & \multicolumn{5}{c}{ Gestational age (weeks) } \\
\cline { 2 - 6 } Parameter & $\begin{array}{c}17-23(\mathrm{n}=185), \\
\text { count }(\%)\end{array}$ & $\begin{array}{c}24-28(\mathrm{n}=184), \\
\text { count }(\%)\end{array}$ & $\begin{array}{c}29-32(\mathrm{n}=112), \\
\text { count }(\%)\end{array}$ & $\begin{array}{c}3-36(\mathrm{n}=76), \\
3 \text { count }(\%)\end{array}$ & $\begin{array}{c}\geq 37(\mathrm{n}=65), \\
\text { count }(\%)\end{array}$ \\
\hline $\begin{array}{l}\text { Ureaplasma urealyticum } \\
\text { and bacterial vaginosis }\end{array}$ & $3(0.9)$ & - & - & - & - \\
$\begin{array}{l}\text { Ureaplasma urealyticum } \\
\text { and Candida }\end{array}$ & $92(28.5)$ & $96(25.9)$ & $44(16.0)$ & $36(19.0)$ & $22(15.3)$ \\
\hline
\end{tabular}

their study, the immune system appears to respond differently to a certain bacteria presence, depending on the environment. In the present study, U. urealyticum infection was detected in the majority of the patients under 28 weeks of gestation (groups 1 and 2) originating from rural areas. By contrast, it was revealed that women from urban areas have vaginal cultures positive to other infectious agents.

Studies have demonstrated that pro and anti-inflammatory responses to bacteria are simultaneously present in the amniotic fluid. The immune response varies due to the environment, gestational age and the pathogens detected. This aspect underlines the need to evaluate patients in a more individualized basis, in order to completely elucidate and comprehend the effects of bacterial pathogens on the immune response and pregnancy $(38,39)$. Vogel et al $(40)$ described a combined effect of vaginal $U$. urealyticum along with the presence of abnormal vaginal flora, that facilitates the ascending of the infection with this particular agent, possibly increasing the risk of preterm delivery. Moreover, another possible explanation is that the microbial disturbances that occur in cases with abnormal vaginal flora enhance the growth of $U$. urealyticum causing a very high Ureaplasma load. Vaginal infection with Candida, also suggests disruptions in the normal constellation of germs in the vaginal flora $(37,40)$.

There is a discrepancy in the results from previously published studies concerning the incidence of different types of vaginal bacterial infections in pregnancy. This may be attributed to the different diagnostic criteria used in the detection of BV and bacteria, as well as differences in the risk profile of pregnant women (parity, use of antibiotic treatment and gestational age at enrollment). The complex mechanism resulting in the association between a certain type of a vaginal flora and $U$. urealyticum colonization in determining preterm labor is likely to be multifactorial. The virulence aspects and the magnitude of the immune response have been reported to be the key for pregnancy outcomes $(38,39)$. Information about the efficiency of antibiotic treatment in intra-amniotic $U$. urealyticum infection is scarce. Insufficient data and the lack of management guidelines force clinicians to adopt empiric antibiotic treatment, culminating in treatment failure in a number of cases $(22,41)$. Pregnant women are not routinely screened for $U$. urealyticum infection because this is not covered by insurance in Romania. Hence, this infection is not usually detected and treated.

In conclusion, this marked association between the $U$. urealyticum intra-amniotic infection and PTB is strongly supported by the existing data and has also been revealed in many previously published studies. The findings of the present study may prove useful in updating clinical practice guidelines, based on local and regional epidemiologic particularities, with the aim of preventing management errors and also underling the need for supplementary first trimester screening for $U$. urealyticum. Further future studies focusing on novel antibiotic regimens protocols for the intra-amniotic infection with $U$. urealyticum are necessary in order to provide insight into treatment and management strategies for bacterial infections and for the 
improvement of long-term perinatal outcomes. Thus, further research is required in order to obtain a better understanding of the association between socioeconomic factors, BV, U. urealyticum infection and the immune system response, which finally lead to adverse outcomes, including premature birth and severe neonatal complications of prematurity.

\section{Acknowledgements}

Not applicable.

\section{Funding}

No funding was received.

\section{Availability of data and materials}

The datasets used and/or analyzed during the current study are available from the corresponding author on reasonable request.

\section{Authors' contributions}

DRM, AU, IEB and CMS were involved in the conception of the study and data interpretation, and also wrote the manuscript. AA, DR, CEM, ID and VLB contributed to data collection and performed the statistical and descriptive analysis. DRM, AU and ID revised the manuscript for important intellectual content and confirm the authenticity of all the raw data. All authors have read and approved the final version of the manuscript.

\section{Ethics approval and consent to participate}

Ethical approval was obtained from the Ethics Committee of the 'Cuza Voda' Obstetrics and Gynecology Clinical Hospital, Iasi and written consent was obtained from all participants (Approval no. 10426/2021).

\section{Patient consent for publication}

Not applicable.

\section{Competing interests}

The authors declare that they have no competing interests.

\section{References}

1. Tibaldi C, Cappello N, Latino MA, Polarolo G, Masuelli G, Cavallo $\mathrm{F}$ and Banedetto C: Maternal risk factors for abnormal vaginal during pregnancy. Int J Gynaecol Obstet 133: 89-93, 2016.

2. Nigro G, Mazzocco M, Mattia E, Di Renzo GC, Carta G and Anceschi MM: Role of the infections in recurrent spontaneous abortion. J Matern Fetal Neonatal Med 24: 983-989, 2011.

3. Ishaque S, Yakoob MY, Imdad A, Goldenberg RL, Eisele TP and Bhutta ZA: Effectiveness of interventions to screen and manage infections during pregnancy on reducing stillbirths: A review. BMC Public Health 11 (Suppl 3): S3, 2011.

4. Pararas MV, Skevaki CL and Kafetzis DA: Preterm birth due to maternal infection: Causative pathogens and modes of prevention. Eur J Clin Microbiol Infect Dis 25: 562-569, 2006.

5. Donders G, Bellen G and Rezeberga D: Aerobic vaginitis in pregnancy. BJOG 118: 1163-1170, 2011.
6. Royal College of Obstetricians and Gynaecologists: Bacterial Sepsis in Pregnancy: Green-top Guideline No.64a. https:// www.rcog.org.uk/globalassets/documents/guidelines/gtg_64a. pdf. Published 2012. Accessed February 2, 2015.

7. RoyalCollegeofObstetriciansandGynaecologists: BacterialSepsis following Pregnancy: Green-top Guideline No.64b. https://www. rcog.org.uk/en/guidelines-research-services/guidelines/gtg64b/. Published 2012. Accessed February 2, 2015.

8. Oliveira CNT, Oliveira MTS, Oliveira HBM, Silva LSC, Freire RS, Santos Júnior MN, Oliveira MV, Timenetsky J, Campos GB and Marques LM: Association of spontaneous abortion and Ureaplasma parvum detected in placental tissue. Epidemiol Infect 148: e126, 2020.

9. Giakoumelou S, Wheelhouse N, Cuschieri K, Entrican G, Howie SEM and Horne AW: The role of infection in miscarriage. Hum Reprod Update 22: 116-133, 2016.

10. Ford HB and Schust DJ: Recurrent pregnancy loss: Etiology, diagnosis, and therapy. Rev Obstet Gynecol 2: 76-83, 2009.

11. Hay P and Czeizel AE: Asymptomatic trichomonas and Candida colonization and pregnancy outcome. Best Pract Res Clin Obstet Gynaecol 21: 403-409, 2007.

12. Fethers KA, Fairley CK, Hocking JS, Gurrin LC and Bradshaw CS: Sexual risk factors and bacterial vaginosis: A systematic review and meta-analysis. Clin Infect Dis 47: 1426-1435, 2008.

13. Donders GG, Van Calsteren K, Bellen G, Reybrouck R, Van den Bosch T, Riphagen I and Van Lierde S: Predictive value for preterm birth of abnormal vaginal flora, bacterial vaginosis and aerobic vaginitis during the first trimester of pregnancy. BJOG 116: 1315-1324, 2009.

14. Rumyantseva T, Khayrullina G, Guschin A and Donders G: Prevalence of Ureaplasma spp. and Mycoplasma hominis in healthy women and patients with flora alterations. Diagn Microbiol Infect Dis 93: 227-231, 2019.

15. Rodríguez N, Fernandez C, Zamora Y, Berdasquera D and Rivera JA: Detection of Ureaplasma urealyticum and Ureaplasma parvum in amniotic fluid: association with pregnancy outcomes. J Matern Fetal Neonatal Med 24: 47-50, 2011.

16. Horner P, Donders G, Cusini M, Gomberg M, Jensen JS and Unemo M: Should we be testing for urogenital Mycoplasma hominis, Ureaplasma parvum and Ureaplasma urealyticum in men and women?-a position statement from the European STI guidelines editorial board. J Eur Acad Dermatol Venereol 32: 1845-1851, 2018.

17. Latino MA, Botta G, Badino C, de Maria D, Petrozziello A, Sensini A and Leli C: Association between genital mycoplasmas, acute chorioamnionitis and fetal pneumonia in spontaneous abortions. J Perinat Med 66: 503-508, 2018.

18. Taylor-Robinson D: Mollicutes in vaginal microbiology: Mycoplasma hominis, Ureaplasma urealyticum, Ureaplasma parvum and mycoplasma genitalium. Res Microbiol 168: 875-881, 2017.

19. Donders GGG, Ruban K, Bellen G and Petricevic L: Mycoplasma/Ureaplasma infection in pregnancy: To screen or not to screen. J Perinat Med 45: 505-515, 2017.

20. Jobe KA, Downey RF, Hammar D, Van Slyke L and Schmidt TA: Epidemiology of sexually transmitted infections in rural southwestern Haiti: The Grand'Anse women's health study. Am J Trop Med Hyg 91: 881-886, 2014.

21. Labbé AC, Frost E, Deslandes S, Mendonça AP, Alves AC and Pépin J: Mycoplasma genitalium is not associated with adverse outcomes of pregnancy in Guinea-Bissau. Sex Transm Infect 78: 289-291, 2002

22. Tantengco OAG and Yanagihara I: Current understanding and treatment of intra-amniotic infection with Ureaplasma spp. J Obstet Gynaecol Res 45: 1796-1808, 2019.

23. Taylor-Robinson D and Lamont RF: Mycoplasmas in pregnancy. BJOG 118: 164-174, 2011.

24. Sweeney EL, Kallapur SG, Gisslen T, Lambers DS, Chougnet CA, Stephenson SA, Jobe AH and Knox C: Placental infection with Ureaplasma species is associated with histologic chorioamnionitis and adverse outcomes in moderately preterm and late-preterm infants. J Infect Dis 213: 1340-1347, 2016.

25. Bick D: Born too soon: The global issue of preterm birth. Midwifery 28: 341-342, 2012.

26. Miyoshi Y,Suga S,Sugimi S,Kurata N, Yamashita Hand Yasuhi I: Vaginal Ureaplasma urealyticum or Mycoplasma hominis and preterm delivery in women with threatened preterm labor. J Matern Fetal Neonatal Med: March 4, 2020 (Epub ahead of print). doi: 10.1080/14767058.2020.1733517. 
27. Waites KB, Katz B and Schelonka RL: Mycoplasmas and ureaplasmas as neonatal pathogens. Clin Microbiol Rev 18: 757-789, 2005.

28. Denoble AE, Wu J, Mitchell CJ, Hughes BL and Dotters-Katz SK: Chorioamnionitis versus intraamniotic infection among preterm deliveries-is postpartum infectious morbidity different? Am J Obstet Gynecol MFM 2: 100176, 2020.

29. Committee on obstetric. Committee opinion No. 712: Intrapartum management of intraamniotic infection. Obstet Gynecol 130: e95-e101, 2017.

30. Le Roy C, Le Hen I, Clerc M, Arfel V, Normandin F, Bébéar C and de Barbeyrac B: The first performance report for the Bio-Rad Dx CT/NG/MG assay for simultaneous detection of Chlamydia trachomatis, Neisseria gonorrhoeae and mycoplasma genitalium in urogenital samples. J Microbiol Methods 89: 193-197, 2012.

31. Capoccia R, Greub G and Baud D: Ureaplasma urealyticum, Mycoplasma hominis and adverse pregnancy outcomes. Curr Opin Infect Dis 26: 231-240, 2013.

32. Yoon BH, Romero R, Lim J, Shim S, Hong JS, Shim JY and Jun JK: The clinical significance of detecting Ureaplasma urealyticum by the polymerase chain reaction in the amniotic fluid of patients with preterm labor. Am J Obstet Gynecol 189: 919-924, 2003.

33. Namba F, Hasegawa $T$, Nakayama M, Hamanaka $T$, Yamashita T, Nakahira K, Kimoto A, Nozaki M, Nishihara M, Mimura K, et al: Placental features of chorioamnionitis colonized with Ureaplasma species in preterm delivery. Pediatr Res 67: 166-172, 2010.

34. Cassel GH, Waites KB, Watson HL, Crouse DT and Harasawa R: Ureaplasma urealyticum intrauterine infection: Role in prematurity and disease in newborns. Clin Microbiol Rev 6: 69-87, 1993.
35. Goldenberg RL, Culhane JF,Iams JD and Romero R: Epidemiology and causes of preterm birth. Lancet 371: 75-84, 2008.

36. Miralles R, Hodge R, McParland PC, Field DJ, Bell SC, Taylor DJ, Grant WD and Kotecha S: Relationship between antenatal inflammation and antenatal infection identified by detection of microbial genes by polymerase chain reaction. Pediatr Res 57: 570-577, 2005.

37. Breugelmans M, Vancutsem E, Naessens A, Laubach $M$ and Foulon W: Association of abnormal vaginal flora and Ureaplasma species as risk factors for preterm birth: A cohort study. Acta Obstet Gynecol Scand 89: 256-260, 2010.

38. Wood AM, Tang M, Truong T, Feldman C, Pieper C and Murtha AP: Vaginal mycoplasmataceae colonization and association with immune mediators in pregnancy. J Matern Fetal Neonatal Med 34: 1-8, 2019.

39. Bhat G, Peltier MR, Syed TA, Drobek CO, Saade G and Menon R: Fetal membrane biomarker network diversity and disease functions induced by intra-amniotic pathogens. Am J Reprod Immunol 69: 124-133, 2013.

40. Vogel I, Thorsen P, Hogan VK, Schieve LA, Jacobsson B and Ferre CD: The joint effect of vaginal Ureaplasma urealyticum and bacterial vaginosis on adverse pregnancy outcomes. Acta Obstet Gynecol Scand 85: 778-785, 2006.

41. Romero R, Espinoza K, Gonçalves LF, Kusanovic JP, Friel L and Hassan S: The role of inflammation and infection in preterm birth. Semin Reprod Med 25: 21-39, 2007.

(7)(9) This work is licensed under a Creative Commons Attribution-NonCommercial-NoDerivatives 4.0 International (CC BY-NC-ND 4.0) License. 